\title{
Comunidade que Sustenta a Agricultura (CSA): panorama das pesquisas brasileiras
}

\author{
Angelina Moreira Melo ${ }^{1}$ \\ Alair Ferreira de Freitas ${ }^{2}$ \\ Daniel Calbino 3
}

\begin{abstract}
Resumo
A Comunidade que Sustenta a Agricultura (CSA) é um sistema de abrangência internacional, que foi implementado no Brasil a partir do ano de 2011 e encontra-se em expansão pelo país. Com o intuito de compreender qual tem sido o foco das pesquisas brasileiras sobre a CSA, o presente artigo propõe-se a realizar a construção do estado da arte sobre esse tema a partir das dissertações e teses já publicadas. Neste sentido, por meio do software IRaMuTeQ realizou-se a análise dos resumos dos trabalhos encontrados e, além disso, foi construído um quadro que apresenta os autores, as universidades, os programas de pós-graduação em que as pesquisas estão vinculadas e as CSAs analisadas. Os resultados indicam que as pesquisas têm sido desenvolvidas por diferentes programas de pós-graduação e o principalmente foco está nas relações interpessoais e no potencial da CSA para a sustentabilidade ambiental.
\end{abstract}

Palavras-chave: Comunidade que Sustenta a Agricultura, Estado da Arte, IRaMuTeQ.

\begin{abstract}
The Community Supported Agriculture (CSA) is an international system, which was implemented in Brazil in 2011 and is expanding throughout the country. In order to understand what has being the focus of Brazilian research on CSA, this article proposes to build the state of the art on this theme through the dissertations and theses already published. In this sense, through the IRaMuTeQ software has been analyzed the summaries of the works found and, in addition, a table was built that presents the authors, the universities, the postgraduate programs to which the research is linked and the CSAs. analyzed. The results indicate that research has been developed by different postgraduate programs and the main focus is on interpersonal relationships and the potential of CSA for environmental sustainability.
\end{abstract}

Keyword: Community Supported Agriculture, State of art, IRaMuTeQ.

\footnotetext{
${ }^{1}$ Mestranda no Programa de Pós-Graduação em Extensão Rural da Universidade Federal de Viçosa (UFV). Bolsista CNPq. angelinamoreiramelo@gmail.com

${ }^{2}$ Doutor em Administração. Professor do Departamento de Economia Rural da UFV. alair.freitas@ufv.br

${ }^{3}$ Doutor em Administração. Professor do Departamento de Ciências Agrárias da Universidade Federal de São João Del Rei - Campus Sete Lagoas (UFSJ-CSL). dcalbino@ufsj.edu.br
} 


\section{Introdução}

A Comunidade que Sustenta a Agricultura (CSA) é um sistema de comercialização de alimentos saudáveis de abrangência internacional que surgiu no Japão, na década de 1960, e desde então tem percorrido o mundo a iniciar-se pela Europa em 1970 e nos Estados Unidos em 1985. Desde o seu surgimento até os dias atuais esse sistema passou por transformações e se reconfigurou, adaptando-se aos novos contextos e ganhando visibilidade. Atualmente ela está presente nos cinco continentes do planeta, abarcando agricultores e consumidores em diferentes regiões para uma nova perspectiva de produção, comercialização, consumo e relações interpessoais.

A CSA não se limita a um circuito comercial. Os consumidores passam a ser denominados de coprodutores, uma vez que participam dos riscos e benefícios da produção ao se comprometerem em realizar um pagamento mensal, antecipadamente, para que os agricultores obtenham o capital necessário para a manutenção dos plantios, sem necessidade de acesso a algum tipo de linha de financiamento. Em contrapartida, os agricultores fornecem, semanalmente, a sua produção para os coprodutores sob a forma de cestas de hortaliças, sendo produtos frescos, da estação e produzidos de forma agroecológica (COOLEY; LASS, 1998; CASTELO BRANCO, et al., 2011; CSA BRASIL, 2017). Assim, produção e consumo são lastreados pela confiança e o sistema se conforma por meio da co-responsabilidade de todos os envolvidos.

A CSA se caracteriza como um movimento contrário ao modelo agroindustrial tradicional e se propõe a desenvolver e fortalecer canais de comercialização de alimentos que priorizem a valorização do alimento local, que promova o desenvolvimento regional, a preservação do meio ambiente e o fortalecimento das relações entre produção e consumo (LAMINE, 2010). Neste sentido, a CSA busca ir além de uma relação instrumental de venda direta entre agricultores e consumidores. O objetivo é que haja a construção de um trabalho coletivo, baseado em uma comunidade que possua laços de confiança e pertencimento, em que agricultores e coprodutores assumam funções específicas para a manutenção do sistema.

A primeira experiência de CSA brasileira surgiu no ano de 2011 na cidade de Botucatu-SP e desde então houve um crescimento exponencial, totalizando em mais de 70 CSAs espalhadas por todas as regiões brasileiras (CSA BRASIL, 2019). O movimento CSA no Brasil tem sido de grande importância para o fortalecimento da agricultura familiar, o escoamento da produção 
agroecológica, o desenvolvimento das regiões, a proposição de novas relações entre agricultorconsumidor e para a preservação do meio ambiente em muitos territórios.

Apesar da relevância dessas experiências e da capilaridade que cada vez mais assumem no país e no mundo, a literatura sobre o tema, ainda é limitada no Brasil. São poucos os trabalhos acadêmicos dedicados a interpretar esse sistema e isso se reduz quando o foco passa a ser a dinâmica de organização e funcionamento do sistema e não apenas as condições técnicoprodutivas. Neste interim, o presente artigo tem como objetivo realizar a construção do estado da arte sobre as pesquisas no âmbito das CSAs no Brasil. Para tanto, será realizada a análise das dissertações e teses publicadas no país e que tiveram o foco analítico nesse tema. Ressalta-se a importância do presente trabalho para a área, pois, a CSA está em processo de expansão no país e representa para agricultores e consumidores uma alternativa ao sistema mercantilista de produção-comercialização-consumo e a promoção do desenvolvimento regional pela possibilidade de escoamento da produção e fortalecimento dos laços entre o rural e o urbano. Assim, compreender qual tem sido o foco das pesquisas já realizadas poderá contribuir para evidenciar as lacunas e possibilidades para futuras pesquisas sobre a CSA e para socializar com a comunidade acadêmica novas linhas e problemas de pesquisa.

\section{Comunidade que Sustenta a Agricultura (CSA): panorama histórico e conceitual}

A Comunidade que Sustenta a Agricultura é conhecida pela sigla CSA, derivada do termo em inglês Community Supported Agriculture. Esse sistema teve suas raízes por volta de 1960, no Japão, quando um pequeno grupo de mulheres preocupadas com o aumento da importação de comidas, no país, e intensivo uso de pesticidas, propuseram para um agricultor local que buscava mercados estáveis, a produzir vegetais e frutas diretamente para elas (BOUGHERARA et al., 2009; WELLS; GRADWELL, 2001). Neste contexto, deu-se o início a uma parceria entre o agricultor e o consumidor, dando origem ao termo Teikei que em livre tradução significa cooperação e existe até os dias atuais.

O Teikei foi pensando para ser além de uma ideia instrumental de compra e venda de produtos agroecológicos, ele é também uma filosofia de vida que busca fazer com que as pessoas (re)pensem a produção e consumo de alimentos. A Associação de Agricultura Orgânica Japonesa definiu o Teikei da seguinte forma: "Uma ideia para criar um sistema de distribuição direta e para realizá-lo, o(s) agricultor(es) e o(s) consumidor(es) têm conversas e contatos para aprofundar sua 
compreensão: ambos fornecem mão de obra e capital para sustentar essa ideia" (HITCHMAN, 2014, p. 1).

O conceito Teikei se espalhou para a Europa durante a década de 1970 e para os Estados Unidos na década 1980 onde sofreu adaptações frente aos novos contextos e uma nova nomenclatura foi criada, a Community Supported Agriculture (CSA) (WELLS; GRADWELL, 2001). A CSA é a sigla que mais se difundiu e ganhou visibilidade, porém, existem grupos, em outros países, que utilizam nomes variados como: Comunidade que Sustenta a Agricultura (CSA); Association for the maintenance of peasant agriculture (AMAP); Soil Association (esquema de caixa); Agricultura Soutenue par la Communaute (ASC) (URGENCI, 2018).

Essas experiências se multiplicaram a partir da América do Norte e Europa durante as décadas 1980 e 1990, atingindo a mais de mil projetos até o final do milênio. A grande maioria desses projetos era pequenas fazendas familiares, que cultivando vegetais orgânicos ou biodinâmicos atraíram membros da região, abarcando uma média de 30 a 50 membros parceiros (URGENCI, 2018). Em quase duas décadas depois, as CSAs criaram raízes, crescendo gradualmente e atingindo o nível de um movimento global (HENDERSON; VAN EN, 2007; MCFADDEN, 2004).

No ano de 2004, na cidade Aubagne, na França, houve a criação da Urgenci - Rede Internacional de Agricultura Apoiada pela Comunidade que funciona como uma associação que tem como missão: “... promover a nível internacional parcerias locais baseadas na solidariedade entre agricultores e consumidores como um compromisso equitativo, onde os agricultores recebem remuneração e os consumidores compartilham os riscos e as recompensas da agricultura" (HITCHMAN, 2014, p. 1).

A Urgenci busca conectar todas as CSAs ao redor do mundo e utiliza para isso um site ${ }^{4}$ que divulga informações e relatórios das experiências e também realizam simpósios internacionais ${ }^{5}$. A conexão de todas as CSAs é realizada através de seus quatro pressupostos, sendo eles: (i) produzir um sistema de alimentos locais e justos para restaurar a soberania alimentar local para todas as regiões e comunidades em todo mundo; (ii) defender a saúde através de alimentos que sejam saudáveis, seguros, nutritivos e minimamente processados, sem

\footnotetext{
${ }^{4}$ Link para acesso ao site da Urgenci: http://urgenci.net/

${ }^{5} \mathrm{~A}$ Urgenci já realizou um total de seis simpósios internacionais que ocorreram em: Aubagne / França - 2004, Palmela/ Portugal - 2005, Aubagne /França - 2008, Kobe / Japão 2010, Monterey / California - 2013, Pequim/ China - 2015.
} 
produtos químicos e aditivos; (iii) construir comunidades que sejam socialmente justas e sustentáveis, que haja responsabilidade cívica nas relações econômicas para se estabelecer uma rede social de solidariedade entre agricultores e consumidores; (iv) abordar questões ambientais e de mudança climática através da construção harmônica entre o homem e a natureza (URGENCI, 2018).

Quanto à organização e gestão das CSAs, a Urgenci evidência em seu site que existem diferentes formatos que se baseiam no contexto social, histórico, geopolítico, agrícola e econômico de cada país ou região em que se desenvolveram (URGENCl, 2018). Neste sentido, Swisher et al., (2012) identifica que existem pelo menos três formatos tradicionais de estruturação das CSAs, sendo eles: (i) não há propriamente o agricultor e todos os membros em formato de uma aliança têm responsabilidades pelo meio de produção, no qual são donos; (ii) os consumidores contribuem com uma parte importante da força de trabalho, porém existem os agricultores que são proprietários das terras; (iii) o agricultor é o dono da terra, das instalações e maquinários e tem responsabilidade pelo processo produtivo agrícola, o apoio dos consumidores consiste em prover o capital por meio da compra de cestas de produtos estabelecendo uma aliança solidária. Este último formato é o mais comum de ser encontrado entre as iniciativas de CSA.

Desta forma, apesar das distinções quanto à gestão das CSAs, elas se conectam por meio de seus pressupostos, que diferenciam as experiências das relações de vendas habituais, pois, se agrega um sentido solidário e participativo no processo de comercialização. Neste sentido, o consumidor não se situa como nas relações tradicionais de comércio, que deseja quantidade, qualidade (questionável) a baixos preços, nesse movimento o elo consumidor "solidário" admite pagar um sobrepreço em relação à média do mercado, quando se agrega um sentido solidário ao produto e oferece melhores condições comerciais ao agricultor, visando propiciar-lhe um padrão de vida mais adequado. (GUZZATTI et al., 2014).

Em contrapartida, os membros da CSA são intitulados de coprodutores, que terão conhecimento de onde vêm os produtos, como são plantados e quem produz. Estabelecendo-se assim, uma conexão intitulada de comunidade, que além de preocupados com a proveniência e natureza dos alimentos, manifestam também um envolvimento comunitário e cívico, em defesa da agricultura local e familiar (DELIND; FERGUSON, 1999).

Neste sentido, Wells e Gradwell (2001, p.1) definem a CSA como: “Uma parceria entre agricultores e consumidores, trabalhando juntos para criar um sistema de produção alimentar 
local". É uma proposição de cooperação que forma uma ligação direta entre os envolvidos, desenvolvendo um mercado alternativo em que os agricultores oferecem a sua produção, semanalmente, aos consumidores sob a forma de cestas de hortaliças, sendo produtos frescos, da estação e produzidos sem agrotóxicos (CASTELO BRANCO, et al., 2011; CSA BRASIL, 2018). Ao participar da CSA os coprodutores se comprometem a realizar um pagamento mensal, antecipadamente, para que os agricultores obtenham o capital necessário à manutenção de sua produção, sem necessidade de acesso a algum tipo de crédito bancário (COOLEY; LASS, 1998; CASTELO BRANCO, et al., 2011).

Desta forma, a CSA pode vir a contribuir para a promoção do comércio justo, o que gera uma melhor remuneração para os agricultores (LAMB, 1994; PEREZ, 2003; ROMAN et al, 2011; CHIFFOLLEAU, 2012). Além disso, com a garantia da entrega das cestas evitam-se flutuações nos preços de mercado e o agricultor, ainda, possui a segurança da venda de seus produtos, o que Ihe proporciona maior disponibilidade de tempo para cuidar do manejo de sua produção (LAMB, 1994; ATANASOAIE, 2011).

Segundo Henderson e Van En (2007); Urgenci (2017) e CSA Brasil (2018) com a participação na CSA, às habilidades dos agricultores passam a ser respeitadas pelos consumidores, que expressam este apreço ao compartilhar os riscos financeiros da produção e relações de amizade. Neste sentido, nos canais de comunicação da Urgenci (2018) está explícito que a CSA representa um compromisso comunitário para a edificação de um sistema agroalimentar local e equitativo, que contribua para que os agricultores possam se concentram em boas práticas agrícolas e manter fazendas produtivas e lucrativas.

Neste contexto, os autores Henderson e Van En (2007) afirmam que a CSA promove a construção de uma comunidade que seja tanto social quanto ecológica. Além disso, contribui para socializar uma perspectiva de comercialização e alimentação diferenciada. Tendo em vista que a manutenção do sistema CSA depende não apenas de elementos materiais, mas, principalmente, de uma série de elementos sociais, que hoje condicionam e definem o que é uma experiência CSA.

Neste ínterim, a trajetória histórica da CSA evidencia o seu sucesso indo além das expectativas e crescendo rumo a um movimento global. Na Europa, as principais iniciativas encontram-se no Reino Unido, França, República Tcheca, Alemanha, Romênia, Eslováquia, Grécia, Hungria, Suíça, Bélgica, Itália, Áustria e Espanha. Na Ásia, é possível encontrar CSAs na China, Índia, Paquistão, Japão e Taiwan. No continente Africano ela está presente na Argélia, 
Benin, Marrocos e Mali. Na Oceania, é possível encontrar iniciativas na Austrália e Nova Zelândia. Por fim, na América há CSAs nos Estados Unidos, Canada, México, Brasil, Chile, Argentina e Equador (URGENCl, 2018).

É evidente, portanto, que a CSA é um movimento global e que continua em crescimento. Trata-se, assim, de um modelo organizativo que conecta produção e consumo, lastreando-se na confiança mútua, mas institucionalizando novos tipos de circuitos curtos de comercialização. A visibilidade desse sistema tem repercutido em diversos países subdesenvolvidos, sendo associado ao fomento da produção de alimentos mais sustentáveis, consumo consciente e valorização da agricultura familiar, rural e urbana. No Brasil a CSA também está sendo difundido. No tópico seguinte se apresenta a trajetória de implementação da CSA no país e um panorama da sua expansão.

\section{Comunidade que Sustenta a Agricultura (CSA) no contexto brasileiro}

A primeira experiência de CSA no Brasil foi inspirada no livro "Farms of Tomorrow Community Supported Farms - Farms Supported Community" (GROH, 1997) que em livre tradução significa "Fazendas do Amanhã - Comunidade que Sustenta a Fazenda - Fazenda que Sustenta a Comunidade". No livro são descritas oito experiências de agricultura biodinâmica em que os agricultores têm a manutenção da produção agrícola e familiar garantida por um grupo de consumidores urbanos que recebem em troca o fornecimento semanal de produtos orgânicos (YAMAMOTO, 2006). O livro foi à inspiração para a implementação da Associação para o Desenvolvimento da Agropecuária Orgânica (ADAO), em 1997, na cidade de Fortaleza - Ceará e que permaneceu em atividade por um período de 10 anos. No entanto, a experiência limitou-se a região de Fortaleza e não se espalhou pelo país (YAMAMOTO, 2006).

No ano de 2011, o artista plástico Hermann Pohlmann, que após sua vivência como cofundador da rede alemã de projetos makeCSA, contribuiu, significativamente, para a implementação da Community Supported Agriculture (CSA) que foi traduzida livremente para o português em Comunidade que Sustenta a Agricultura e implementada, inicialmente, na cidade de Botucatu - São Paulo e denominada de CSA Demétria, que existe até os dias atuais. No mesmo ano (2011), no Fórum Mundial Social em Porto Alegre - Rio Grande do Sul, o conceito CSA foi apresentado como um dos favoritos e com grande potencial de futuro (ABELN, 2015). 
Assim, as experiências de CSAs, a partir de 2011, se espalharam pelo país, atingindo diferentes regiões. Neste contexto, em 2015 houve a criação da Associação Comunitária CSA Brasil, que é uma organização sem fins lucrativos e que contribui para a formação e apoio de novos grupos de CSA em todo o país (TORRES, 2017; CSA BRASIL, 2018). Em sua página na internet a CSA Brasil apresenta-se a partir da seguinte descrição:

CSA BRASIL é uma organização sem fins lucrativos que constrói, como modelos, projetos agrícolas baseados na comunidade, nos quais os agricultores podem se orientar para garantir um futuro a pequenos empreendimentos agrícolas. A CSA BRASIL também acompanha e supervisiona estes projetos em forma de rede, que já se espalhou por todo o Brasil (...). A CSA BRASIL é representada na rede Urgenci internacional (CSA BRASIL, 2019).

A criação do CSA Brasil possibilitou o surgimento de novas experiências no país, pois, o apoio e suporte disponibilizado por eles contribuíram para difundir a experiência para várias regiões. Além disso, foi realizado o mapeamento das CSAs e foi possível identificar que há 79 depósitos que representam as CSAs e o local de recebimento das cestas, também existem 53 unidades de produção que são as fazendas dos agricultores e 24 grupos no país que estão em articulação para implementação da primeira CSA (CSA BRASIL, 2019). Contudo, ressalta-se que não há um levantamento preciso sobre a quantidade de CSAs espalhadas pelo país, pois, a CSA Brasil quantifica apenas aquelas que se associam a eles. Assim, pode haver um número maior do que as experiências citadas.

Quanto à localização das CSAs, os principais estados em que são encontradas as experiências são: São Paulo, Rio de Janeiro, Minas Gerais, Rio Grande do Sul, Mato Grosso do Sul, Distrito Federal, Pernambuco, Paraná, Santa Catarina, Amazonas. Além disso, pode-se observar que desde a constituição da primeira CSA no Brasil, no ano de 2011, até o atual momento, houve um crescimento considerável nas experiências, o que aponta o seu potencial de expansão.

Sobre as pesquisas realizadas no contexto nacional, a literatura ainda é incipiente, mas encontra-se em crescimento. Neste sentido, após o panorama apresentado sobre o surgimento da CSA, sua expansão pelo mundo e a sua chegada ao Brasil, será analisado, a seguir, qual o foco das pesquisas no âmbito nacional e os possíveis apontamentos para estudos futuros. 


\section{Metodologia}

O presente trabalho se caracteriza pela construção do estado da arte que pode ser definido como as pesquisas que realizam uma revisão da literatura acadêmica sobre a produção de um tema específico em uma determinada área do conhecimento. A importância desse tipo de pesquisa deve-se a sua profundidade de análise, o que possibilita a construção dos temas mais estudados dentro do assunto em que se investiga, identifique os grupos teóricos mais pesquisados e evidencie as lacunas das pesquisas e apontamentos para estudos futuros (FERREIRA, 2002; ROMANOWSKI e ENS, 2006).

Além disso, sistematizar as pesquisas que foram desenvolvidas sobre determinado tema, possibilita a construção de diferentes ângulos em que um objeto vem sendo estudado e poderá contribuir para investigações mais profundas e com novos enfoques (FERREIRA, 2002). Neste sentido, para a construção do estado da arte sobre a Comunidade que Sustenta a Agricultura (CSA) o presente trabalho realizou uma busca, no dia 30 de Julho de 2019, na Biblioteca Brasileira de Dissertações e Teses da Capes por pesquisas sobre a CSA.

Foram encontradas 08 dissertações e 02 teses que continham no título, resumo ou palavra-chave as seguintes palavras: Comunidade que Sustenta a Agricultura; Community Supported Agriculture e CSA. Ressalta-se que o presente trabalho manteve seu foco analítico nas dissertações e teses já publicadas sobre a CSA, pois, ao realizar uma busca por artigos nacionais sobre o tema, foram encontrados poucos trabalhos e a maioria deles já contidos nas dissertações e teses selecionadas.

Para compreender qual o foco das pesquisas, foram analisados os resumos de todas as dissertações e teses (no total foram 10 trabalhos) e foram definidas as categorias das pesquisas com o auxílio do IRaMuTeQ (Interface de R pour les Analyses Multidimensionnelles de Textes et de Questionnaires) que é um software livre que realiza análises de conteúdo, lexicometria e análise do discurso. Optou-se pelo auxílio do software, pois, o mesmo contribui para a organização e separação das informações, o que possibilita a eficiência na localização dos segmentos de texto e agilidade na definição das categorias de análise. Além disso, realizou-se a categorização das pesquisas, identificando o ano das publicações, os autores, as universidades, os programas de pós-graduação e o departamento em que estão vinculados. 


\section{O panorama das pesquisas sobre a CSA no Brasil}

As pesquisas em nível internacional sobre a CSA iniciaram-se a partir da década de 1990 e atualmente existe um amplo leque de autores que analisam as experiências (LAMB, 1994). No âmbito nacional, a primeira CSA surgiu a partir do ano de 2011 e por conseguinte houve a sua expansão pelo país. Desta forma, as publicações de pesquisas nacionais são recentes, pois, os primeiros trabalhos foram publicados a partir do ano de 2016 (CASTELO BRANCO et al., 2011).

Assim, até a data do dia 30 de maio de 2019 tinham sido identificadas na literatura um total de 10 pesquisas, sendo 08 dissertações e 02 teses. Constata-se que até o presente momento são poucas as publicações sobre a CSA, mas, a partir delas já é possível ter apontamentos sobre como têm sido essa experiência no Brasil e compreender o foco destas pesquisas poderá trazer novas diretrizes de estudo sobre a CSA.

Neste sentido, o quadro 01 apresenta a relação de autores das dissertações e teses encontradas, bem como as universidades e os programas de pós-graduação em que estavam vinculados, o ano das publicações e a quantidade e localização das CSAs que foram analisadas. A partir do quadro 01 é possível identificar que a maioria das pesquisas foi desenvolvida por mulheres, pois, em um total de 10 publicações, 07 são de autoria feminina e 03 masculinos. Quanto à localização geográfica das universidades, é identificado que 07 pesquisas foram desenvolvidas em universidades da região sudeste, 02 no centro-oeste e 01 na região sul do país.

Outro aspecto identificado é a interdisciplinaridade dos programas de pós-graduação em que as pesquisas estão vinculadas, o que indica que as CSAs estão sendo analisadas por diferentes perspectivas. Além disso, as dissertações e teses concentraram as suas pesquisas nas CSAs de Belo Horizonte (03 dissertações e 01 tese), São Paulo (03 dissertações e 01 tese) e Brasília (02 dissertações).

Nesse sentido, é possível inferir que até o presente momento as pesquisas convergem para as CSAs que se encontram na região sudeste e centro-oeste. Uma possível justificativa para esse fenômeno deve-se ao fato destas regiões concentrarem o maior número de experiências que se caracterizam por ser consolidadas e inseridas nos grandes centros urbanos do país, o que possivelmente pode indicar um volume maior de participantes. 
Quadro 01: Dissertações e teses sobre a CSA no Brasil

\begin{tabular}{|c|c|c|c|c|}
\hline Autor(a) & Universidade & $\begin{array}{c}\text { Programa de } \\
\text { Pós-Graduação }\end{array}$ & $\begin{array}{c}\text { Ano de } \\
\text { Publicação }\end{array}$ & $\begin{array}{c}\text { Localização das CSAs } \\
\text { analisadas }\end{array}$ \\
\hline Daniele Eckert & $\begin{array}{l}\text { Universidade Federal } \\
\text { do Rio Grande do Sul }\end{array}$ & $\begin{array}{l}\text { Mestrado em } \\
\text { Administração }\end{array}$ & 2016 & $\begin{array}{l}2 \text { em Belo Horizonte - } \\
\text { MG }\end{array}$ \\
\hline $\begin{array}{l}\text { Liliane Ubeda } \\
\text { Morandi Rotoli }\end{array}$ & $\begin{array}{l}\text { Universidade } \\
\text { Estadual Paulista }\end{array}$ & $\begin{array}{l}\text { Mestrado em } \\
\text { Agronegócio e } \\
\text { Desenvolvimento }\end{array}$ & 2016 & $\begin{array}{l}14 \text { do estado de São } \\
\text { Paulo }\end{array}$ \\
\hline $\begin{array}{l}\text { Maria Luiza de } \\
\text { Andrade Benini }\end{array}$ & $\begin{array}{l}\text { Universidade } \\
\text { Estadual de } \\
\text { Campinas }\end{array}$ & $\begin{array}{l}\text { Mestrado em } \\
\text { Ciências Humanas e } \\
\text { Sociais Aplicadas }\end{array}$ & 2016 & 1 em São Carlos-SP \\
\hline $\begin{array}{l}\text { Camila Lombardi } \\
\text { Torres }\end{array}$ & $\begin{array}{l}\text { Universidade de } \\
\text { Brasília }\end{array}$ & Mestrado em Design & 2017 & 03 em Brasília - DF \\
\hline $\begin{array}{l}\text { Thomaz Lanna } \\
\text { Neves }\end{array}$ & $\begin{array}{l}\text { Universidade do } \\
\text { Estado de Minas } \\
\text { Gerais }\end{array}$ & Mestrado em Design & 2017 & $\begin{array}{l}2 \text { em Belo Horizonte- } \\
\text { MG e } 01 \text { no Rio de } \\
\text { Janeiro-RJ }\end{array}$ \\
\hline $\begin{array}{l}\text { Alanda Lopes } \\
\text { Baptista Martins }\end{array}$ & $\begin{array}{l}\text { Universidade Federal } \\
\text { Fluminense }\end{array}$ & $\begin{array}{l}\text { Doutorado em } \\
\text { Geografia }\end{array}$ & 2017 & $\begin{array}{l}01 \text { em Botucatu - SP; } 1 \\
\text { na Alemanha. }\end{array}$ \\
\hline $\begin{array}{l}\text { Gustavo Serra } \\
\text { Santana }\end{array}$ & $\begin{array}{l}\text { Universidade de } \\
\text { Brasília }\end{array}$ & $\begin{array}{l}\text { Mestrado em } \\
\text { Agronegócio }\end{array}$ & 2018 & 5 em Brasília - DF \\
\hline $\begin{array}{l}\text { Joana Ortega de } \\
\text { Lima Amorim }\end{array}$ & $\begin{array}{l}\text { Universidade Federal } \\
\text { de São Carlos }\end{array}$ & $\begin{array}{l}\text { Mestrado em } \\
\text { Agroecologia e } \\
\text { Desenvolvimento } \\
\text { Rural }\end{array}$ & 2018 & $\begin{array}{l}3 \text { em São Paulo-SP; } 1 \\
\text { em São Carlos-SP e } 5 \\
\text { CSAs na Alemanha. }\end{array}$ \\
\hline $\begin{array}{l}\text { Fernanda Antunes } \\
\text { de Oliveira }\end{array}$ & $\begin{array}{l}\text { Universidade Federal } \\
\text { de Minas Gerais }\end{array}$ & $\begin{array}{l}\text { Mestrado em } \\
\text { Administração }\end{array}$ & 2018 & $\begin{array}{l}2 \text { em Belo Horizonte - } \\
\text { MG }\end{array}$ \\
\hline Vander Luiz Aguiar & $\begin{array}{l}\text { Pontifícia } \\
\text { Universidade Católica } \\
\text { - MG }\end{array}$ & $\begin{array}{l}\text { Doutorado em } \\
\text { Administração }\end{array}$ & 2018 & $\begin{array}{l}2 \text { em Belo Horizonte - } \\
\text { MG e } 1 \text { em Londres }\end{array}$ \\
\hline
\end{tabular}

Fonte: Elaborado pelos autores

Contudo, ressalta-se a importância da expansão das pesquisas para outras regiões, como o sul, o norte e o nordeste, pois, assim será possível construir um quadro mais fiel à realidade das CSAs do Brasil, a partir de uma perspectiva que abrange as experiências que se inserem em diferentes contextos do país.

\section{0 foco das pesquisas}

Com o propósito de dotar a análise dos dados também em uma perspectiva quantitativa, foi realizada a Classificação Hierárquica Descendente (CHD) dos resumos dos trabalhos analisados, por meio do software IRaMuTeQ. A CHD segmenta parcelas dos textos analisados (segmentos de texto) em função dos significados das palavras e dos vocábulos utilizados pelos 
autores. Por meio da CHD, foi possível compreender o foco das pesquisas sobre CSA no Brasil a partir da visualização da categorização das palavras em um organograma e da análise dos segmentos de textos identificados em cada uma das categorias.

O corpus total foi constituído de dez resumos de dissertações (8) e teses (2) e foram segregados pelo software 81 segmentos de textos (ST) - trechos dos resumos -, mas aproveitados na classificação 51 , que correspondem a $71,60 \%$ dos segmentos. O conteúdo analisado foi categorizado em seis classes: Classe 1 com 12 ST $(20,7 \%)$, Classe 2 com 8 ST (13,79\%), Classe 3 com 11 ST (18,97\%), Classe 4 com 10 ST (17,24\%), Classe 5 com 9 ST (15,52\%) e Classe 6 com 8 ST (13,79\%). A Figura 01, a seguir, representa a CHD gerada pelo software e são apresentadas as palavras que obtiveram maior porcentagem quanto à frequência média, às classes identificadas e acima delas um resumo.

Neste sentido, conforme apresentado na figura 1, a classe 1 possui o mesmo grau hierárquico de similaridade em relação as classes 2, 3, 4 e 5 e por isso podem ser agrupadas conjuntamente, pois, ambas evidenciam que o foco das pesquisas está no potencial da CSA, como um movimento contra hegemônico, para o fornecimento de alimentos agroecológicos, principalmente, nos grandes centros urbanos.

Além disso, as pesquisas analisam a sua contribuição para desenvolver a sustentabilidade ambiental e também focam nas relações interpessoais que são desenvolvidas nos grupos de CSAs e apontam que as mesmas ainda são fragilizadas e que a estrutura organizativa de gestão precisa ser transparente e atender as necessidades do(s) agricultor(es) e do(s) consumidor(es) para que haja o seu fortalecimento.

Quanto a classe 6, o foco está na possibilidade da CSA em apresentar-se a partir de um sistema agroalimentar alternativo e contra hegemônico, focando principalmente na transição agroecológica. A classe 6 também representa um resumo geral das demais classes, mas ressaltase que sozinha ela não é capaz de responder qual o foco dos trabalhos analisados. Desta forma, a partir da análise de todas as classes é possível compreender que o principal foco das pesquisas brasileiras está relacionado com as relações interpessoais presentes nas CSAs e os efeitos desse sistema para a sustentabilidade ambiental. 
Figura 1: Dendrograma da Classificação Hierárquica Descendente

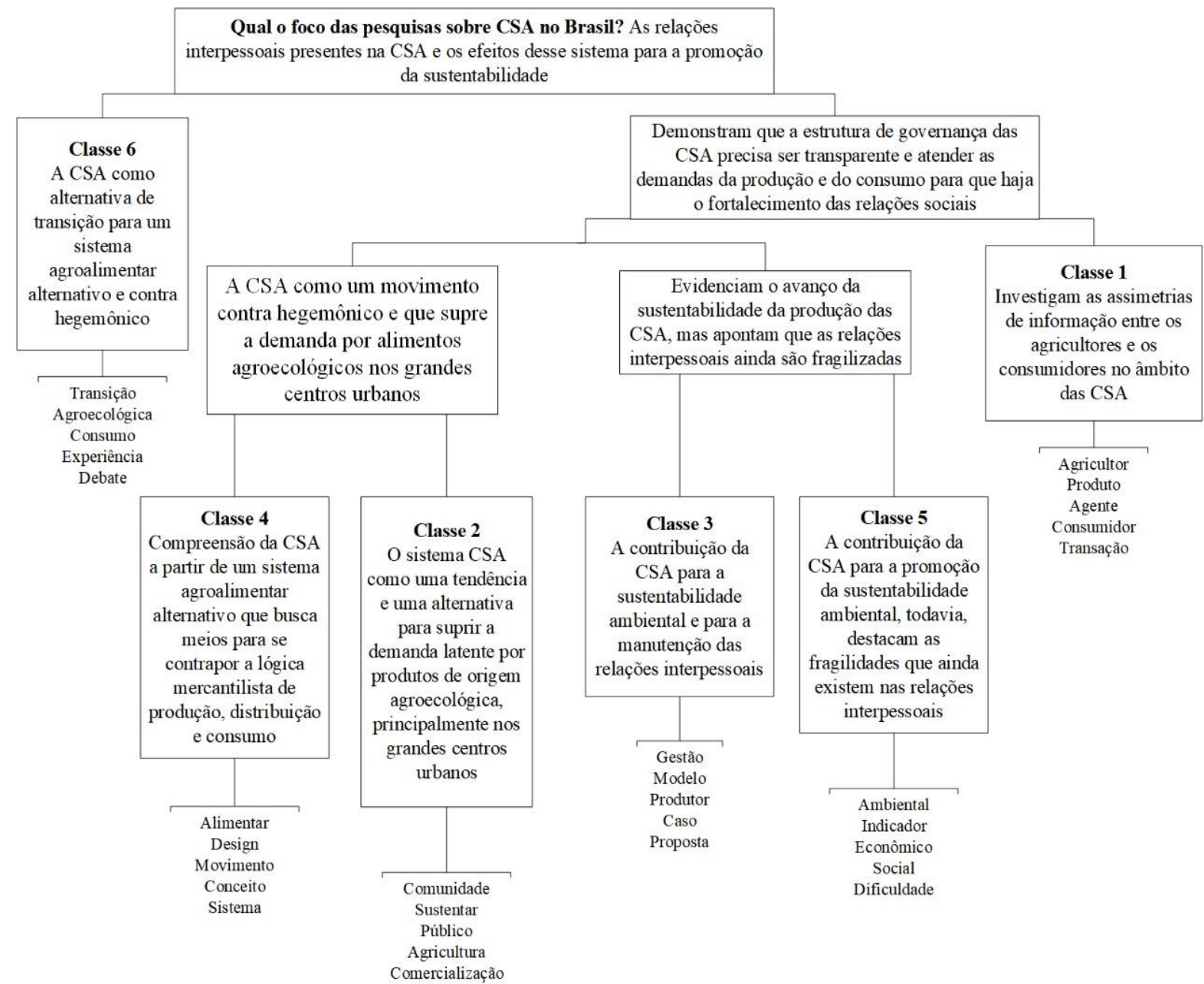

Fonte: Elaborado pelos autores a partir dos resultados gerado pelo software IRaMuTeQ, 2019.

Pode-se inferir que as pesquisas têm apresentado dados importantes sobre as CSAs brasileiras, como exemplo, têm-se os consumidores que estão inseridos no contexto mercantilista, do consumo industrializado dos grandes centros urbanos, e que conseguem se contrapor a essa lógica e articularem-se em prol de um movimento como a CSA. Assim, segundo Eckert (2016) ao analisar duas CSAs na cidade de Belo Horizonte, Capital do Estado de Minas Gerais, que foram implementadas a partir da iniciativa da sociedade civil, a autora aponta que os grupos podem contribuir para reversão do êxodo rural, diminuição da pobreza, acesso a alimentos saudáveis e na preservação do meio ambiente. Aspectos que também podem ser evidenciados em outras CSAs analisadas nas pesquisas, como em São Paula e Brasília.

No entanto, apesar dos pontos positivos evidenciados nas pesquisas, elas também mostram que há desalinhamento quanto aos acordos formais e informais firmados pelos 
agricultores e coprodutores. Este aspecto já vem sendo discutido na literatura internacional desde a década de 1990 e assemelham-se com a realidade brasileira, apresentada nas pesquisas.

Dessa maneira, conforme afirmam os autores Groh; McFadden (1997), Lang (2010), O’hara; Stagl (2002) os desacordos são vistos, principalmente, com a rotatividade dos coprodutores e a sua pouca integração ao grupo e no que se referem aos agricultores, os mesmos demonstram pouco envolvimento com a gestão da CSA e pouca socialização com o grupo. Assim, apesar das pesquisas sobre a CSA no Brasil estarem inseridas em um contexto diferente de outros países, é evidente que os desafios enfrentados são similares.

\section{Perspectivas e possibilidades para futuras pesquisas sobre a CSA}

Com o intuito de contribuir para futuras pesquisas sobre a CSA no Brasil, serão apresentados alguns apontamentos e lacunas, a partir da análise das pesquisas já realizadas. Um primeiro aspecto identificado é que as pesquisas tem se concentrado apenas na região sudeste e centro-oeste, mas, existe mais de 70 experiências cadastradas no site CSA BRASIL em diferentes regiões do país, como o nordeste, norte e sul. Além disso, existem grupos que não estão cadastradas no site, ampliando ainda mais o número de CSAs para futuras pesquisas.

Outro aspecto identificado é que existem apenas duas pesquisas que realizaram um diálogo com experiências internacionais, a dissertação de Amorim (2018) e a tese de Aguiar (2018). Desta forma, conforme afirma o site da Urgenci (2018) a CSA espalhou-se pelo mundo e está presente nos cinco continentes, assim, estudos comparativos entre as CSAs do Brasil e outros países da América Latina, América do Norte e Europa seria importante para compreender os limites e possibilidades e as estratégias aplicadas por eles que poderiam ser empregadas no contexto brasileiro.

Por fim, para futuras pesquisas, há outras óticas de análise que podem ser realizadas. A exemplo, um dos pressupostos da CSA é a constituição de comunidades, para além do âmbito físico e geográfico, o intuito é que os membros dos grupos sejam socialmente justos, prezem pela sustentabilidade, tenham responsabilidade cívica e relações sociais pautadas pela solidariedade (URGENCI, 2018).

Neste sentido, Lamb (1994) afirma que a constituição da comunidade entre os agricultores e consumidores é o elemento essencial para as CSAs e por isso é preciso que haja esforços para que seja desenvolvida uma comunidade pelos membros do grupo, pois esse é o 
elemento chave de muitas CSAs bem-sucedidas. Em similaridade, Attra (2006) aponta que a ideia original da CSA é promover a comunidade e a cooperação entre os membros.

Neste contexto, é evidente que o termo comunidade se faz presente não apenas na nomenclatura da CSA, mas, também é um de seus pilares. Assim, analisar as CSAs brasileiras à luz da comunidade é uma pauta de pesquisa que o presente trabalho traz como contribuição para área, tendo em vista que, essa também é uma lacuna de pesquisa presente na literatura internacional.

Neste sentido, Pole e Gray (2013) afirmam que é preciso analisar o que acontece com o C da CSA, pois há uma lacuna de pesquisas que investiguem a CSA à luz da Comunidade. Os autores apontam, ainda, que uma visão mais completa desse sistema só será possível após a realização de trabalhos empíricos que analisem a comunidade, utilizando um escopo analítico que considere as particularidades de cada grupo, a partir do local no qual estão inseridos (LANG, 2010; O'HARA; STAGL, 2002; POLE; GRAY, 2013).

\section{Considerações finais}

Ao realizar as análises das pesquisas pode-se inferir que o foco delas têm sido compreender as relações interpessoais entre agricultores e coprodutores das CSAs e analisar/avaliar o potencial dos grupos para promover a sustentabilidade ambiental a partir da transição agroecológica e preservação do solo e da água. Além disso, foi possível elucidar que as pesquisas têm sido realizadas, principalmente, por mulheres, a maioria das universidades em que estão vinculadas é da região sudeste e centro-oeste e os programas de pós-graduação são de diferentes áreas. Quanto as CSAs analisadas, percebe-se uma concentração na região sudeste e centro-oeste, principalmente, nas cidades de São Paulo, Belo Horizonte e Brasília.

Neste interim, os apontamentos trazidos no presente trabalho podem contribuir para futuras pesquisas no país ao evidenciar que há um leque de CSAs, em diferentes regiões, que ainda não foram estudadas. Além disso, as pesquisas internacionais podem contribuir para se (re)pensar nos limites, possibilidades e novas pautas de pesquisa para as CSAs brasileiras.

Assim, um novo olhar para a CSA proposto é através da comunidade que se constitui a partir da implementação do grupo. Até o presente momento não há nenhuma pesquisa neste âmbito, mas acredita-se que compreender as comunidades que têm sido constituídas em torno desse sistema poderá contribuir para um melhor entendimento dos efeitos da CSA na vida de 
seus participantes e como isso é representado por eles no contexto econômico, social e ambiental.

Outro aspecto que pode ser analisado nas CSAs são os seus membros, pois, além da natureza das relações é importante compreender quem são as pessoas que estão se mobilizando em torno destas experiências e isso representa identificar esse público e o que de fato representa a CSA para essas pessoas nos contextos em que elas estão inseridas.

\section{Referências}

ABELN, Johanna. CSA Demetria as a pioneer project for CSA Brasil. Urgenci. 2015. Link para acesso: http://urgenci.net/csa-demetria-in-brazil/. Acesso em: 07/06/2019

AGUIAR, Vander Luiz. Empresas Sociais de Agricultura Urbana: um estudo nas Comunidades que Sustentam a Agricultura em Belo Horizonte e Londres. Tese de Doutorado. Universidade Católica de Minas Gerais, 2018.

AMORIM, Joana Ortega de Lima. Comunidade que Sustenta a Agricultura (CSA) em São Paulo e agricultura solidária (solawi) na Alemanha: construindo indicadores sociais, econômicos e ambientais. Dissertação (Mestrado em Agroecologia e Desenvolvimento Rural). Universidade Federal de São Carlos. Araras, 2018.

ATANASOAIE, G. Distribution channels on the organic foods market. JOURNAL of Horticulture, Forestry and Biotechnology. 2011.v.15(3), p. 19-25.

BENINI, Maria Luiza de Andrade. Entre lugares e espaços: uma caminhada no grupo de CSA (Community Supported Agriculture) de Barão Geraldo. Cadernos de Agroecologia, v. 11, n. 2, 2017.

BOUGHERARA, Douadia; GROLLEAU, Gilles; MZOUGHI, Naoufel. Buy local, pollute less: What drives households to join a community supported farm? Ecological Economics, New York, v. 68, n. 5, p. 1488-95, 2009.

CASTELO BRANCO M; LIZ RS; ALCÂNTARA FA; MARTINS HAG; HANSON JC. Agricultura apoiada pela comunidade: poderia a experiência dos agricultores americanos ser útil para os agricultores urbanos brasileiros? Horticultura Brasileira 29: 43-49. 2011.

COOLEY JP; LASS DA, F. Consumer benefits from Community Supported Agriculture Membership. A comparison of CSA share versus retail produce value. Review of Agricultural Economics 20: 227-237. 1998.

CSA BRASIL. Comunidade que Sustenta a Agricultura - BRASIL. 2018. Disponível em: http://www.csabrasil.org/csa/category/publicacoes. Acesso em: 05/05/2019.

CHIFFOLEAU, F.. Des circuits courts de commercialisation des produits alimentaires biologiques. RMT Dév $A B$ - AXE 1 - partenariats - fiche no 2: les circuits courts de commercialisation em $A B$, 2009. 
DELIND, L; FERGUSON, A. Is This a Women's Movement? The Relationship of Gender to Community-Supported Agriculture in Michigan. Human Organization: Summer, Vol. 58, No. 2, pp. 190-200, 1999.

ECKERT, D., \& Meira, F. B. A mercantilização em contramovimento: Relações de reciprocidade e coesão social na agricultura sustentada pela comunidade em Minas Gerais. 2016. 235 f. Dissertação (Mestrado em Administração) - Universidade Federal do Rio Grande do Sul, Porto Alegre. 2016.

FERREIRA, N. S. O. As Pesquisas denominadas "Estado da Arte". Educação \& Sociedade, ano XXIII, no 79, p. 257-272, 2002.

GROH, Trauger; MCFADDEN, Steve. Farms of tomorrow revisited: community supported farms farm supported communities. Kimberton, PA: Biodynamic Farming and Gardening Association, 1997.

GUZZATTI et al. Novas relações entre agricultores familiares e consumidores: Perspectivas recentes no Brasil e na França. Organizações Rurais \& Agroindustriais, Lavras, v. 16, n. 3, p. 363-375, 2014.

HENDERSON, Elisabeth; VAN EN, Robyn. Sharing the harvest: a citizen's guide to community supported agriculture. 2. ed. Vermont: Chelsea Green Publishing Co., 2007.

HITCHMAN, Judith. Advocacy, social movements, short distribution chains and policy: an illustrated analytical approach. Urgenci, Working Paper $n^{\circ} 1.2014$.

Link:https://urgenci.net/working-paper-on-advocacy-and-short-distribution-chains/. Acessado em 29/05/2019

LAMB, G. Community Supported Agriculture Can It Become the Basis for a New Associative Economy? The Threefold Review, 1994.

MARTINS, Alanda Lopes Baptista. Agricultura Apoiada pela Comunidade ou comunidade apoiada pela agricultura? A relação campo-cidade pela ética da solidariedade. Tese (Doutorado em Geografia) - Universidade Federal Fluminense, 2017.

MCFADDEN, Steven. Community farms in the 21st century: poised for another wave of growth? Kutztown, PA: Rodale Institute, 2004. Disponivel em:

http://newfarm.rodaleinstitute.org/features/0104/csa-history/part1.shtml. Acesso em: 07/09/2018.

NEVES, Thomaz Lana. Design para o sistema alimentar: um estudo comparativo de sistemas produto-serviço para produção, distribuição e comercialização de alimentos. Dissertação (mestrado)- Universidade do Estado de Minas Gerais, Escola de Design. 2017

OLIVEIRA, Fernanda Antunes de. Comunidade que sustenta a agricultura: entendendo as CSAS de Belo Horizonte e analisando suas possibilidades e desafios. Dissertação de Mestrado.

Universidade Federal de Minas Gerais. 2018.

PEREZ, J. Community Supported Agriculture on the Central Coast: The CSA Member Experience. Center for Agroecology and Sustainable Food Systems, UC Santa Cruz Publication, 2003.

ROMANOWSKI, J. P.; ENS, R. T. As pesquisas denominadas do tipo "estado da arte" em educação. Diálogo Educacional, v. 6, n. 19, p. 37-50, 2006.

ROMAN, C. et al. Agriculture de proximité, circuits courts: les territoires Aquitainss' impliquent: guide pourl action 2011. Bordeaux: Réseau Rural em Aquitaine, 2011. 
SANTANA, G. S. Impactos ambientais e socioeconômicos do uso da água nas CSAs do DF. 2018, 163 f. Dissertação. (Mestrado em Agronegócio) - Faculdade de Agronomia e Medicina Veterinária, Universidade de Brasília, Brasília, 2018

SWISHER, M, E., et al. ¿Qué Es una Granja Apoyada por una Alianza de Consumidores? Family Youth and Community Sciences, Servicio de Extensión Cooperativa de la Florida, Instituto de Alimentos y Ciencias Agrícolas, Universidad de la Florida, 2012.

TORRES, Camila Lombardi. Comunidade que sustenta a agricultura: a reaplicação da tecnologia social a partir dos casos pioneiros em Brasília. 2017. Dissertação de mestrado. Universidade de Brasília

URGENCI. The International Network for Community Supported Agriculture. Aubagne, FR:

Urgenci, 2018. Disponível em: http://urgenci.net. Acesso em: 05/09/2018a.

. The International Network for Community Supported Agriculture. Aubagne, FR:

Urgenci, 2017. Disponível em: https://urgenci.net/vison-and-mission/. Acesso em: 28/08/2018b.

WELLS, B; GRADWELL, S. Gender and resource management: Community supported agricultura as caring-pratice. Agriculture and Human Values, 18, 107-119, 2001.

YAMAMOTO, A. Por que continuamos juntos? Reciprocidade, mudança cultural e relações de poder entre o urbano e o rural. 2006. 145 f. Dissertação (Mestrado em Sociologia). Universidade Federal do Ceará. Fortaleza. 2006. 